\title{
The relationship between dominance and leadership in a flock of ewes
}

\author{
WILLIAM E. ADDISON and EDWARD C. SIMMEL \\ Miami University, Oxford, Ohio 45056
}

\begin{abstract}
We examined the nature of the relationship between dominance and leadership in a flock of ewes, identifying the pattern of social structure within the group and the frequencies of leadership behavior. We found that the pattern of social structure in the flock was a multilevel arrangement, with several levels of dominance apparent. A chi-square test of goodness of fit performed on the leadership frequencies indicated that leading behavior was not a purely random process. In addition, our results clearly suggest a distinct relationship between dominance and leadership in these animals, with the most dominant member of the group also displaying the most leading behavior.
\end{abstract}

Although studies of social behavior in domestic animals are fairly numerous, such research on sheep and goats is minimal. We feel that these animals make especially appropriate subjects for studies of social behavior, as they show the tendency to form social groups characterized by relatively well-defined dominance structures. Past studies have shown that sheep (Geist, 1971; Scott, 1945) and goats (Coblentz, 1976; Ross \& Scott, 1949; Stewart \& Scott, 1947) are indeed quite social, and individual animals are rarely seen apart from the group.

The available research in the area suggests that leadership in domestic sheep is not a clear process. Hafez (1975) discusses some key factors in the process, the most important of which are the age, sex, and relationship of the group members. He points out, however, that many commercial flocks contain no natural leader, since unrelated animals are typically brought together to form the group. In addition, other investigators have suggested that there is little or no relationship between dominance and leadership in domestic sheep. In a study of social organization in a herd of goats (Addison \& Baker, Note 1), we did not find this to be the case. Although we did not directly examine this relationship in the previous study, it was apparent that the dominant members of the group were also the ones that did most of the leading.

There were two related purposes for the present investigation. The first purpose was the identification of the nature of the social structure of the group, that is, the determination of the specific dominant and subordinate rankings of the flock members as measured by analyzing various measures of agonistic behavior (threats, displacements, butting). The second purpose was the determination of whether any particular animals were

We thank Nolan Crawford for graciously providing the study area and the subjects. Requests for reprints should be addressed to William E. Addison, Department of Psychology, Miami University, Oxford, Ohio 45056. usually seen leading the flock, thus indicating that a "leadership hierarchy" existed within the group. In addition, a combination of the answers to these two problems would yield evidence suggesting a relationship between dominance and leadership.

\section{METHOD}

\section{The Study Area}

The observation area consisted of approximately .81 hectare (2 acres) located about $3 \mathrm{~km}$ north of Oxford, Ohio. The area was approximately rectangular and contained a small shed in the southwest corner. The shed provided shelter for the sheep, and they spent a great deal of time there. The area also contained several large trees and a small mound from which the observer was afforded a good and unobtrusive view of the entire study area.

\section{Subjects}

The flock consisted of eight ewes, ranging in age from 1 to 4 years. The subjects were members of a larger group of 25 sheep (24 ewes and $1 \mathrm{ram}$ ) from which they were separated and brought to the study area in mid-May 1979. Details concerning the individual histories of the sheep (breed, lineage, etc.) were unknown, except for the fact that all of the subjects had been reared together (within the large group) since birth. The animals were identified by collars of various colors that were placed on the subjects by the investigator. An abbreviation was then assigned to each animal based on the color of the collar.

\section{Observation and Recording}

The subjects were given approximately 2 months to adapt to their new surroundings. During this period, the investigator made frequent appearances at the study area so that the animals could adapt to his presence. Actual observations began in midJuly and continued through the end of October 1979.

The method of observation consisted primarily of recording interactions involving three measures of agonistic behavior (threats, displacements, butting), as well as any "leading" behavior that occurred. In addition, relevant information pertaining to other social behaviors (e.g., sniffing, etc.) was recorded in a descriptive manner.

The distance maintained between the observer and the subjects varied with different conditions, but at no time did the distance become so great as to make identification of particular animals impossible. On the average, the observation distance was 
approximately $20-30 \mathrm{~m}$. For greater distances, a pair of standard $(7 \times 35$ power) field glasses was used to identify individual subjects.

The observation schedule was designed to provide a cross section of behavior throughout the day $(0700-2000 \mathrm{~h})$. The arrangement of-observation periods within the daily framework was randomly determined to ensure that all time periods were equally represented in the data. Since it has been suggested that $100 \mathrm{~h}$ of observation time is necessary to identify a group's social structure (Wilson, 1975), a total of $100 \mathrm{~h}$ was allocated for the project.

The following specific behaviors were recorded during the project.

(1) Threats-This category includes such displays as charging and lowering the head as if to butt. No physical contact is involved in these behaviors, although a threat may clearly lead to a physical confrontation.

(2) Displacements-We defined a displacement as an interaction between two animals in which one animal, through an explicit or implicit action, causes the other animal to move from a given location. Physical contact, an explicit action, may or may not be involved in a displacement. For example, the mere approach of a dominant animal (an implicit action) may cause a subordinate animal to move away, with no physical contact between the two animals.

(3) Butting-This category includes nearly all of the physical confrontations witnessed among the ewes. The category also includes pushing and shoving, since it has been suggested that these types of interactions predominate in the competitive behavior of sheep (Hafez, 1975).

Frequency counts were recorded for instances of agonistic behavior, and the specifics of each interaction (e.g., aggressor, victim) were also recorded. The three measures of agonistic behavior clearly do not exhaust all types of possible interactions. However, we believe that, taken together, they provide an index that can be used to formulate the social structure of the group.

In addition, frequency counts for leadership were also recorded. Since domestic sheep tend to stay in single file and travel upon well-defined tracks when approaching or leaving a grazing area (Hafez, 1975), it was a fairly simple matter to identify the group leader in these instances. The frequency counts were then analyzed for deviation from randomness by using a chi-square test for goodness of fit.

\section{RESULTS}

The pattern of social structure in the flock was a multilevel arrangement, with several levels of dominance apparent. This was determined by an analysis of the animals' involvements in agonistic behavior (threats, displacements, butting). Agonistic behavior was recorded and analyzed in terms of the number of incidents and the members of the flock with which each animal was involved. Displacements were especially useful in this analysis, since it was assumed that a subordinate animal rarely displaces a dominant member of the group. For this reason, a table showing the victims and aggressors in displacements is included (Table 1). Data from the other two measures of agonistic behavior were consistent with those shown in Table 1. The data support the dominant and subordinate rankings within the flock, as listed in Table 1. For example, the fact that zeros frequently appear below the diagonal indicates that the proposed hierarchy is relatively accurate.

It is apparent that BF was the dominant member of the flock. She was a victim of displacements only twice,
Table 1

Number of Displacements Per Animal

\begin{tabular}{lccccccccc}
\hline & \multicolumn{10}{c}{ Victim } & & $\begin{array}{c}\text { Total } \\
\text { Aggres- }\end{array}$ & BF & W & R & O & BR & G & BL & BU & Attacks \\
\hline BF & - & 2 & 4 & 3 & 2 & 2 & 4 & 2 & 19 \\
W & 1 & - & 8 & 17 & 0 & 4 & 6 & 3 & 39 \\
R & 1 & 4 & - & 10 & 5 & 3 & 3 & 5 & 31 \\
O & 0 & 1 & 5 & - & 0 & 4 & 5 & 9 & 24 \\
BR & 0 & 0 & 1 & 1 & - & 1 & 0 & 1 & 4 \\
G & 0 & 0 & 1 & 0 & 0 & - & 0 & 2 & 3 \\
BL & 0 & 0 & 0 & 0 & 0 & 0 & - & 0 & 0 \\
BU & 0 & 0 & 0 & 0 & 0 & 0 & 0 & - & 0 \\
\hline
\end{tabular}

yet she was the aggressor in such interactions with every other member of the flock. This occurrence is of crucial importance; the combination of the low number of times BF was observed to be a victim plus the fact that she displaced every other member at least twice serves to substantiate her dominant position. No other member of the group demonstrated this unique combination of behaviors. On this basis, we concluded that BF was the sole member of the uppermost dominance level.

The second level of dominance included Subjects $\mathrm{W}$, $R$, and $O$. These three sheep engaged in a relatively large number of displacements (as well as the other measures of agonistic behavior), but the key factor here is that they almost never displaced the dominant member of the group (BF). Consistent with their position in this subdominant level, $\mathrm{W}, \mathrm{R}$, and $\mathrm{O}$ were involved in a relatively large number of agonistic interactions among themselves. They were also frequently involved with subordinate members of the flock.

The third level of dominance included BR and G. The fact that these two ewes engaged in any displacements as aggressors separates them from the lowest level of the social structure. The fourth level included BL and BU, and it is apparent from Table 1 why these two were so classified. Neither was observed to be an aggressor in any agonistic interaction, yet both were frequently the victims of such encounters.

Figure 1 shows the number of times that each sheep was observed leading the movement of the flock. It is apparent from the figure that $\mathrm{BF}$ was seen leading the group more often than any other member. Of a total of 56 instances observed, BF was observed leading the flock 21 times, or $38 \%$ of the total. A chi-square test of goodness of fit was conducted on the leadership frequencies, and we found that the observed frequencies differed significantly $(p<.05)$ from a purely random arrangement. Clearly, the relatively large number of instances attributed to BF was responsible for the significance of these results.

\section{DISCUSSION}

The results show that leadership in domestic sheep is a more salient feature of the animals' social behavior than was previously thought. Our finding that one particular animal did nearly half of the leading in this flock strongly suggests that this behavior is not a completely random process. 


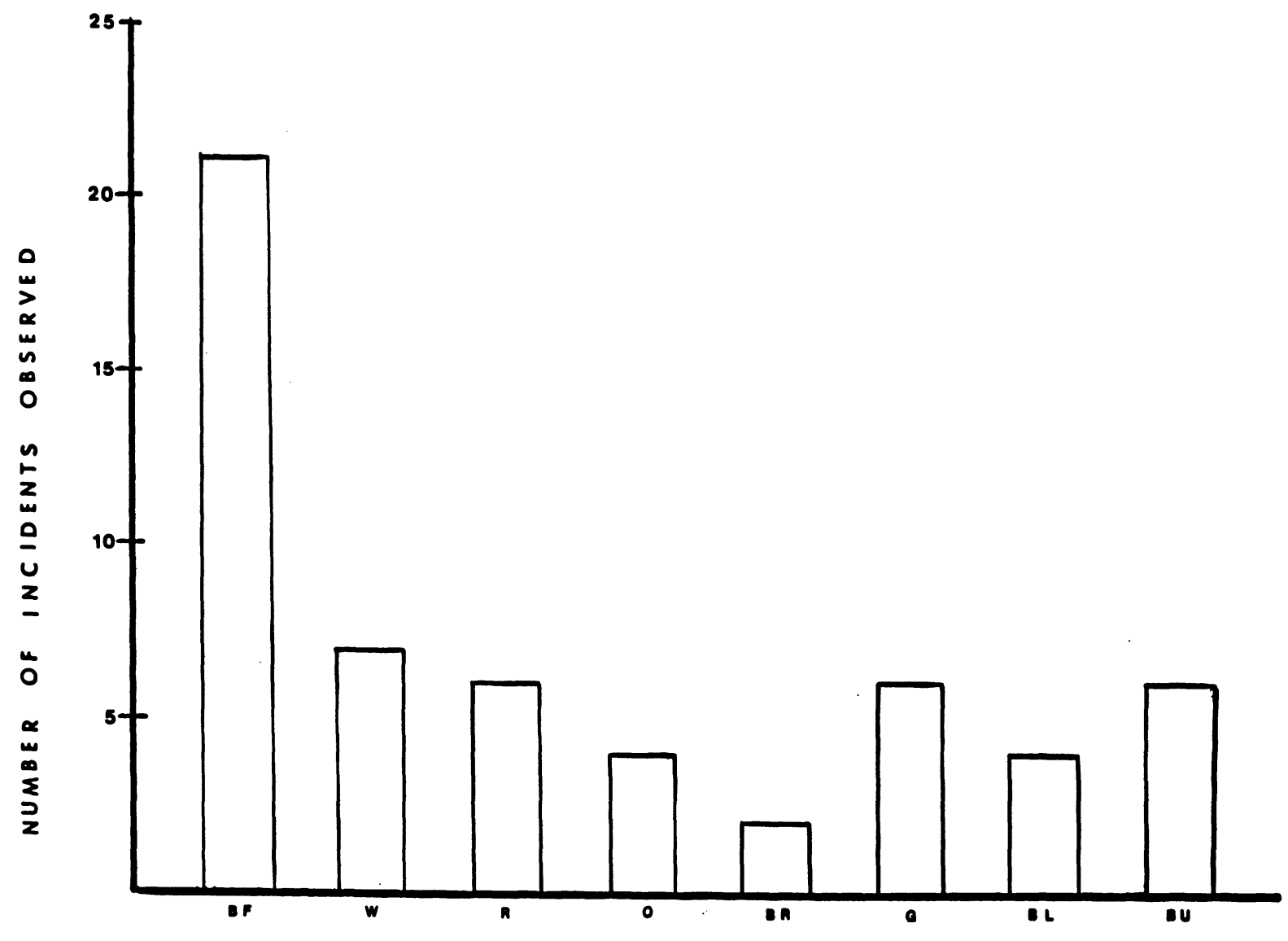

SU B JECTS

Figure 1. Frequency of flock leading by subject.

More important, the results clearly suggest a distinct relationship between dominance and leadership in these animals. Although our results show no direct correspondence between an animal's position in the dominance hierarchy and the number of times it leads the group, it seems that the most dominant member of the group is also likely to demonstrate the most leading behavior.

Further research is needed to determine more precisely the nature of this relationship. It is likely that a number of factors contribute to the strength of the dominance-leadership relationship, including the age-sex composition of the group and the degree of competition among the members. It is our opinion that a continuing investigation of these and other factors will illuminate the details of this relationship and aid in a more thorough understanding of social organization.

\section{REFERENCE NOTE}

1. Addison, W. E., \& Baker, E. Agonistic behavior and social organization in a herd of goats as affected by the introduction of nonmembers. Manuscript submitted for publication, 1980.

\section{REFERENCES}

Coblentz, B. E. Functions of scent urination in ungulates with special reference to feral goats. American Naturalist, 1976 , 110, 117-128.

GeIST, V. Mountain sheep: A study in behavior and evolution. Chicago and London: University of Chicago Press, 1971.

HAFEz, E. S. E. The behaviour of domestic animals. London: Bailliere Tindall, 1975.

Ross, S., \& Scotт, J. P. Relationships between dominance and control of movement in goats. Journal of Comparative and Physiological Psychology, 1949, 42, 75-80.

ScotT, J. P. Social behavior, organization, and leadership in a small flock of domestic sheep. Comparative Psychological Monographs, 1945, 18, 1-29.

StewarT, J. C., \& ScotT, J. P. Lack of correlation between leadership and dominance relationships in a herd of goats. Journal of Comparative and Physiological Psychology, 1947, 40, 255-264.

WILSON, E. O. Sociobiology. Cambridge, Mass: Harvard University Press, 1975.

(Received for publication March 8, 1980.) 